\title{
Temporal, Spatial and Tissue-Specific Expression of a Myogenin-lacZ Transgene Targeted to the Hprt Locus in Mice
}

BioTechniques 27:154-163 (July 1999)

\author{
Jay L. Vivian, William H. \\ Klein and Paul Hasty \\ University of Texas M.D. \\ Anderson Cancer Center, \\ Houston, TX, USA
}

\footnotetext{
ABSTRACT

A lacZ transgene, expressed by the myogenin promoter, was introduced into the mouse hypoxanthine phosphoribosyltransferase (Hprt) locus by gene targeting in embryonic stem cells. Embryos between E10.5-E18.5 days were analyzed for expression of the transgene after staining for $\beta$-galactosidase activity. Transgene expression was restricted to the skeletal muscle lineages reflecting a similar temporal and spatial pattern previously demonstrated for the endogenous myogenin gene. Additionally, a second transgene, MC1tk, showed expression in $87 \%$ of the clones when targeted to Hprt. This strategy, called targeted transgenesis, provides control for analyzing promoter sequences and for comparing various transgenes expressed by the same promoter.
}

\section{INTRODUCTION}

The analysis of transgenic mice has been a common method to evaluate promoter sequences and gene-product function $(13,25,33)$. Transgenes have been integrated into the genome of mammalian cells and animals by a variety of techniques, including pronuclear injection, viral integration and knockins. However, there are problems associated with each of these techniques that can complicate interpretation or limit application. Therefore, the development of other methods to introduce transgenes into mammalian cells and animals might improve control and broaden application.

Pronuclear injection has been the most commonly used method to introduce transgenes into mice, and the problems that arise from pronuclear injection have been well described (25). First, large chromosomal deletions, inversions and duplications are frequently generated with transgene integration. These alterations could potentially mutate nearby genes, resulting in an unwanted phenotype that complicates analysis of the transgene $(9,10,36)$. Sec- ond, variable levels and patterns of transgene expression are observed between founder mice because of concatemerization of the transgene and chromosomal positional effects (2). Third, mosaic expression of the transgene can occur due to position-effect variegation (28) or intrachromosomal recombination within the transgene concatemer (29). Transgenic mice derived from multiple founders must be analyzed and compared to control for these variables.

Transgenes can be introduced directly into embryos by a variety of techniques, including retroviral and adenoviral-mediated gene transfer and DNA:lipopolyamine-mediated gene transfer. However, these procedures still present many of the same problems as pronuclear injection, and DNA: lipopolyamine-mediated gene transfer has only been used for transient expression $(12,31,33)$. In addition, stable transmission of the transgene through the germ line is difficult.

Embryonic stem (ES) cell technology has been used to produce transgenic mice. Promoterless transgenes have been integrated into a target locus by homologous recombination; a method 
referred to as a "knock-in" $(13,35)$. The goal is twofold: (i) to disrupt the target gene and (ii) to express the transgene within the target gene's promoter. In addition, large fragments of DNA in a yeast artificial chromosome (YAC) clone have been introduced into the genome of ES cells (8). These approaches lessen the need to understand the promoter sequences necessary for regulated expression and were proven effective in analysis of the transgene product; however, they are ineffective for analysis of promoter sequences.

To address these problems, a procedure called targeted transgenesis (18) was developed. This procedure introduces a single copy of a transgene into a known location. The first reported attempt at targeted transgenesis was expression of a transgene targeted to the third exon of hypoxanthine phosphoribosyltransferase (Hprt) (22), in ES cells (32). The transgene was lacZ-driven by a promoter containing the polyoma virus enhancer and herpes simplex virus (HSV)-thymidine kinase $(t k)$ promoter (called MC1; Reference 20). Unfortunately, variable expression was observed between different cell types, and transgenic mice were not generated.
More recently, a bcl-2 transgene, expressed by the $\beta$-actin promoter, was targeted upstream of Hprt and shown to be uniformly expressed between different founder mice (4). However, expression at the cellular level was not studied.

In this report, targeted transgenesis was evaluated for temporal and tissuespecific expression at the cellular level using the myogenin promoter. Myogenin is a member of the $M y o D$ family of basic-helix-loop-helix transcription factors (11) and is important for skeletal muscle development (14). Expression of myogenin is tightly restricted to the skeletal muscle lineage $(5,24)$. Analysis of the myogenin promoter revealed that $1565 \mathrm{bp}$ of sequences immediately preceding the myogenin translation initiation codon was sufficient to direct tissue-specific expression of lacZ (6). This transgene, Myo1565lacZ, was targeted to the second intron of Hprt in ES cells to test for tissue-specific expression. Transgenic mice were generated, and appropriate temporal, spatial and tissue-specific expression was observed in all transgenic embryos. In addition, expression of the HSV-tk gene by the MC1 promoter (MCltk) was tested for clonal repro-

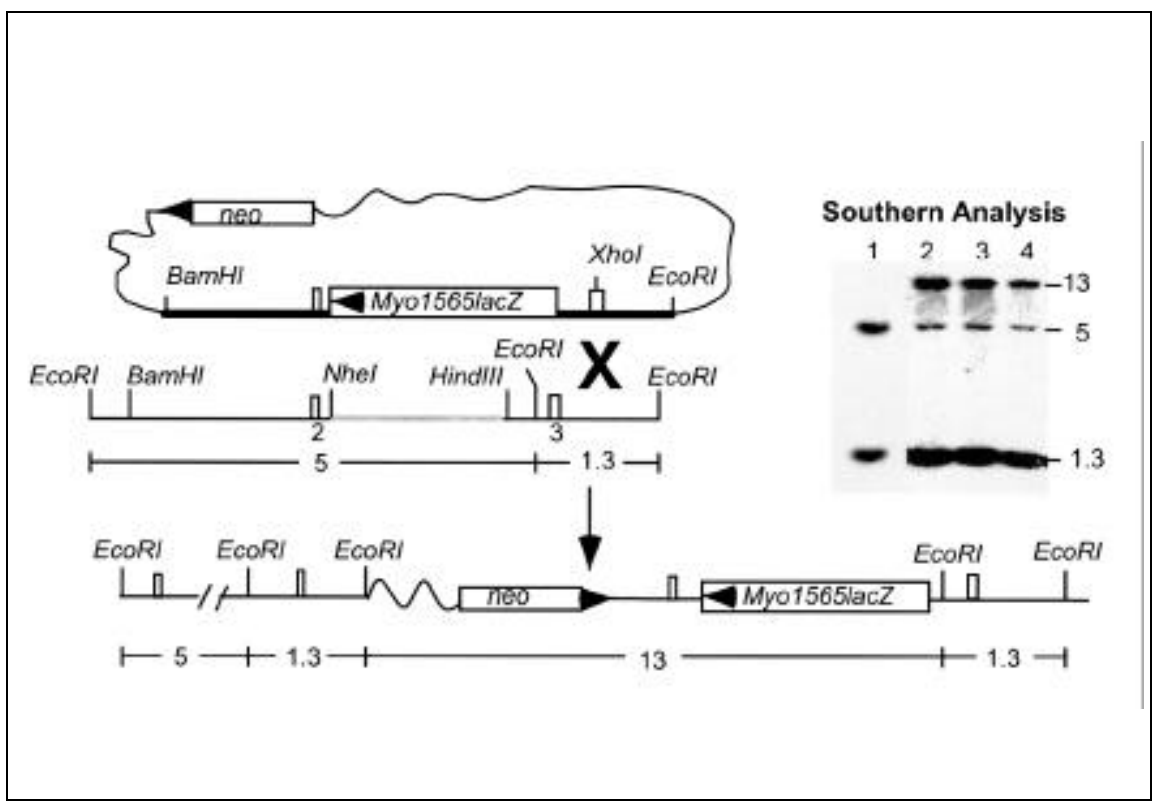

Figure 1. Targeting Myo1565lacZ to hprt. Diagram of the vector and Hprt allele. Thick line, homology to Hprt in vector. Thin line, genomic Hprt. Wavy line, plasmid backbone. Gray line, deleted Hprt sequences in the targeting vector. Arrows point to transcriptional orientation. Size of EcoRI-restricted fragments are shown in $\mathrm{kb}$. $\mathbf{X}$ represents the crossover junction. Southern analysis: DNA, extracted from the yolk sac, was digested with $E c o$ RI, separated by electrophoresis, blotted and hybridized to exons 2 and 3 of Hprt. Lane 1, non-transgenic embryo; lanes 2-4, transgenic embryos. 


\section{Research Report}

ducibility of expression when targeted to Hprt. For clones with MCltk targeted to Hprt, $87 \%$ exhibited sufficient expression for sensitivity to $1-\left(2^{\prime}\right.$-deoxy- 2 '-fluoro- $\beta$-D-arabinofuranosl)-5iodouracil (FIAU).

\section{MATERIALS AND METHODS}

Construction of Insertion Vector to Hprt with Myo1565lacZ (IVH-MyoZ)

A SacI-EcoRI fragment that contains exons 2 and 3 was used for $\mathrm{Hprt}$ (22) homology. Myo1565lacZ (6) was inserted into the NheI and HindIII sites of Hprt intron 2, removing about $2.3 \mathrm{~kb}$ of this intron. The positive-selection cassette, PGKneobpA, was positioned in the bacterial plasmid, pTZ (Amersham Pharmacia Biotech, Piscataway, NJ, USA). The vector was linearized in the Hprt sequences at a unique XhoI site.

\section{Construction of Insertion Vector to Hprt with HSV-1 Thymidine Kinase (IVH-tk)}

A SacI-EcoRI fragment that contains exons 2 and 3 was used for Hprt homology. MCltk (20), derived from the HSV-tk gene was inserted into the plasmid backbone (pTZ) of the targeting vector. The positive-selection cassette, PGKneobpA, was positioned in exon 3 of Hprt at the XhoI site. The vector was linearized in the Hprt sequences at a unique NheI site.

\section{Gene Targeting with IVH-MyoZ and IVH-tk}

AB1 ES cells were grown on a monolayer of mitotically inactivated SNL 76/7 STO (21) cells in M15 (15\% fetal calf serum [FCS; HyClone Laboratories, Logan, UT, USA], Dulbecco's modified Eagle medium [DMEM; Life Technologies, Gaithersburg, MD, USA], $10^{-4} \mathrm{M} \beta$-mercaptoethanol, 2 $\mathrm{mM}$ L-glutamine, $49.5 \mathrm{U} / \mathrm{mL}$ penicillin and $38.8 \mu \mathrm{g} / \mathrm{mL}$ streptomycin). Cells were trypsinized and resuspended in phosphate-buffered saline (PBS;
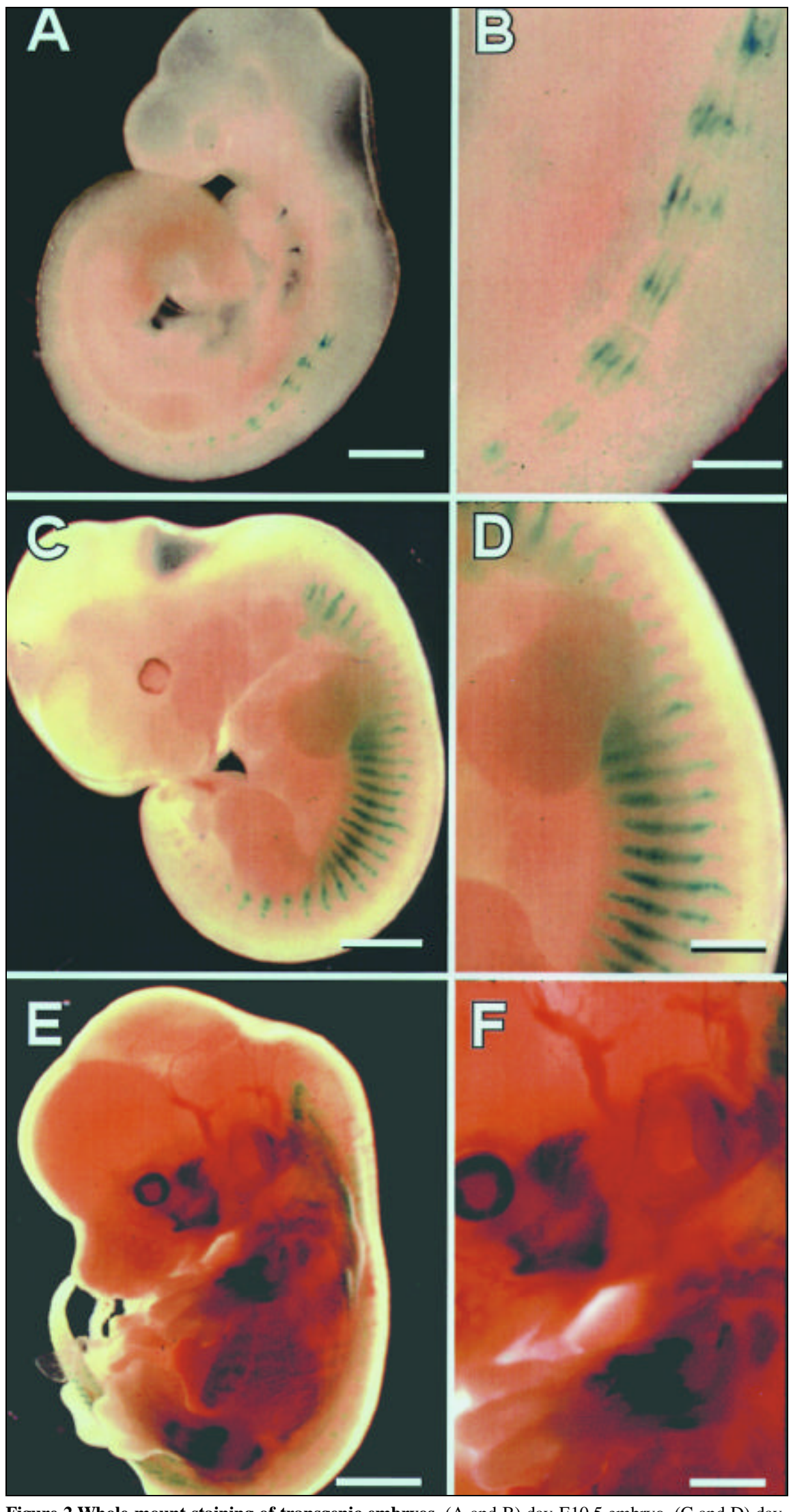

Figure 2. Whole-mount staining of transgenic embryos. (A and B) day-E10.5 embryo. (C and D) dayE11.5 embryo. (E and F) day-E13.5 embryo. Scale bars: (A) 50, (B) 20, (C) 80 , (D) 40 , (E) 200, (F) $80 \mu \mathrm{m}$. 
$\mathrm{Ca}^{2+}, \mathrm{Mg}^{2+}$-free) for transfection with IVH-MyoZ cut with XhoI or IVH-tk cut with NheI (10 $\mu \mathrm{g}$ DNA electroporated in $10^{7}$ cells/mL PBS at $230 \mathrm{~V}$, $500 \mu \mathrm{F}$ using a Gene Pulser ${ }^{\circledR}$ System [Bio-Rad, Hercules, CA, USA]). One electroporation was plated onto a single $10-\mathrm{cm}$ plate. G418 (180 $\mu \mathrm{g}$ active ingredient/mL M15) was added $24 \mathrm{~h}$ later to select for transfected cells, and 6-thioguanine (TG; $10^{-5} \mathrm{M}$ final concentration) was added five days later to select for targeted cells. Eleven days after the electroporation, G418-resistant $\left(\mathrm{G} 418^{\mathrm{R}}\right)$ plus TG-resistant $\left(\mathrm{TG} \mathrm{G}^{\mathrm{R}}\right)$ clones were picked for Southern analysis.

\section{Southern Analysis}

Determination of gene targeting at $H$ prt has been previously described for both insertion and replacement vectors with a variety of probes $(17,38)$. Genomic DNA was extracted from ES cells for Southern blot analysis by the micro-extraction procedure (26). Digested DNA, separated by electrophoresis through a $0.7 \%$ gel in TAE buffer $(0.04 \mathrm{M}$ Tris-acetate, $0.001 \mathrm{M}$ EDTA, $\mathrm{pH}$ 8.0) was transferred to a Hybond ${ }^{\circledR}-\mathrm{N}+$ filter (Amersham Pharmacia Biotech) and hybridized to random-primed labeled probe. For cones transfected with IVH-MyoZ, EcoRI was used for restriction, and Hprt exons 2 and 3 isolated from cDNA cut with HincII and HpaII was used for probe (22). For IVH-tk, BamHI was used for restriction, and a 400-bp fragment from intron 1 cut out with BamHI to $X b a \mathrm{I}$ was used for probe (38).

\section{Generation of Transgenic Mice}

Transgenic mice were generated by injecting targeted ES cells into dayE3.5 C57BL/6 embryos as previously described (3).

\section{Whole Mount Stain}

Tissues were isolated and stained for $\beta$-galactosidase ( $\beta$-gal) activity as described (7). Embryos at day E10.5E13.5 were stained as whole mounts. Limbs from day-E18.5 embryos were dissected, skinned and stained.

\section{Histology}

5-bromo-4-chloro-3-indolyl- $\beta$-D-galactopyranoside (X-gal)-stained hind limbs were fixed in $10 \%$ buffered formalin, processed and embedded in paraffin using standard procedures (19). Sagittal sections $(6-\mu \mathrm{m}$ thick) were cut and lightly stained with nuclear Fast $\operatorname{Red}^{\circledR}$.

\section{MC1tk Expression in ES Cell Clones Targeted with IVH-tk}

G418R + TGR ES cell clones transfected with IVH-tk were tested for MCltk expression by survival in a base analogue, $0.2 \mathrm{mM}$ FIAU. ES cell clones that express HSV-tk will die after metabolizing FIAU, while those clones that fail to express HSV-tk will survive; FIAU is lethal to cells only after it is metabolized. G418R + TGR clones were picked and expanded on a 96-well plate for five days and then replica-plated onto two 96-well plates. One plate was selected in FIAU, and the other was not. Cell growth was visualized for five days.

\section{RESULTS}

\section{Generation of Myo1565lacZ Transgenic Mice}

An insertion vector, IVH-MyoZ, was used to introduce Myo1565lacZ into the Hprt locus. Hprt was chosen as the integration site for four reasons. (i) Deletion of Hprt does not cause a phenotype in mice unless they are predisposed to an adenine phosphoribosyltransferase deficiency (37). (ii) Hprt is a member of the purine salvage pathway and expressed in all cell types at low levels; therefore, it is a house-keeping gene, and chromosomal positional effects should be less a factor as for other loci. (iii) Selection for gene targeting is efficient because Hprt is single-copy in male cells, and its disruption can be selected in tissue culture with a toxic base analog, 6-thioguanine (TG). Finally, because Hprt is on the Xchromosome, it is subject to $\mathrm{X}$-inactivation. This permits evaluation of the transgene product for cell autonomy by comparing mice that express the transgene in all cells (males and homozygous females) to mice that express the 


\section{Research Report}

transgene in only a fraction of cells (hemizygous females).

Myo1565lacZ was introduced into Hprt intron 2 by gene targeting (Figure 1). The targeting vector, IVH-MyoZ, contained sequences homologous to Hprt that flanked the reporter (Myo1565lacZ) and a positive-selection cassette (PGKneobpA) outside the Hprt sequences. The vector was linearized within the Hprt homology at the XhoI site to make an insertion vector. Cells were transfected by electroporation and selected in G418 for integration into a chromosome and in TG for targeting to Hprt. Only one $\mathrm{G} 418^{\mathrm{R}}+\mathrm{TG}^{\mathrm{R}}$ clone survived out of three transfections. The $\mathrm{G} 418^{\mathrm{R}}+\mathrm{TG}^{\mathrm{R}}$ clone was analyzed by Southern analysis to confirm targeting, which resulted in the appropriate bands for an insertion event (13, 7 and $1.3 \mathrm{~kb}$ ). However, the increased intensity of the 13-kb band compared with the $5-\mathrm{kb}$ band indicated that two to three copies of the vector integrated into this site, perhaps a consequence of limiting target homology (16). Thus, targeting frequency would likely be improved by lengthening the homology that flanks the double-strand break. It is unlikely that two to three copies of the target vector would affect tissue specificity; therefore, the targeted clone was used to generate chimeric mice after injection into C57BL/6 embryos. The chimeric males were bred to $\mathrm{C} 57 \mathrm{BL} / 6$ females to generate transgenic mice.

\section{Myo1565lacZ Expression is Specific to Skeletal Muscle Lineage when Targeted to Hprt}

Myogenin expression is limited to the skeletal muscle lineage $(5,24)$. Transcripts are first detected in the myotome by day E8.5 and in the limb buds by E11.5, with expression greatly declining around birth. Transgene expression was evaluated between E10.5-E18.5. Either yolk sacs (E10.5-E13.5) or tails (E18.5) were removed for genotyping by Southern blot analysis (Figure 1) to identify transgenic and non-transgenic embryos. $\beta$-gal expression was analyzed in these embryos by whole-mount staining in X-gal. Non-transgenic embryos failed to stain blue $(n=22)$; however, all transgenic embryos $(n=18)$ stained blue in a pattern restricted to the skeletal muscle lineage for all time points observed. Staining was first observed in the myotome of day-E10.5 embryos (Figure 2, A and B), which progressed to the intercostal region by day E11.5 (Figure 2, C and D). Staining was also observed in the limb buds and developing facial musculature (Figure $2, \mathrm{E}$ and $\mathrm{F}$ ). $\beta$-gal activity was observed at the cellular level by histological sections of limbs from day-E18.5 embryos. Staining was clearly restricted to skeletal muscle and was not present in bone or other tissues (Figure 3). Therefore, expression of Myo1565lacZ targeted to Hprt, recapitulates the temporal and spatial expression pattern of the endogenous myogenin gene.

\section{Expression of HSV-tk Transgene Targeted to Hprt}

Transgene expression can vary from clone to clone for a variety of reasons, including position-effect variegation and mutation. The effects of clonal variation of transgene expression, targeted to Hprt, were examined. An HSV-tk gene expressed by the $M C 1$ promoter (MCltk), was targeted to the second in- tron of Hprt. MCltk was chosen to test transgene expression because HSV-tk metabolizes FIAU to a product that is toxic to mammalian cells. Therefore, cells expressing MCltk can be identified by their sensitivity to FIAU.

MCltk was introduced into Hprt intron 2 by gene targeting (Figure 4 ). The targeting vector (IVH-tk) contained sequences homologous to Hprt, MCltk and PGKneobpA. The vector was linearized in Hprt homology at the NheI site. Cells were transfected by electroporation and selected in G418 for chromosomal integration and in TG for targeting to Hprt. G418 $\mathrm{R}+\mathrm{TG}^{\mathrm{R}}$ cells were analyzed by Southern blot analysis to confirm targeting (Figure 4). Targeting can occur by either an insertion event (insertion of the entire vector into Hprt due to a single crossover) or a gene-replacement event (replacement of endogenous Hprt sequences with vector-derived Hprt sequences due to crossovers at both sides of PGKneobpA). Thus, $M C 1 t k$ is incorporated into Hprt only after vector insertion. Using Southern analysis, 39 G418R + TGR $^{\mathrm{R}}$ clones were targeted by vector insertion, and seven were targeted by gene replacement.

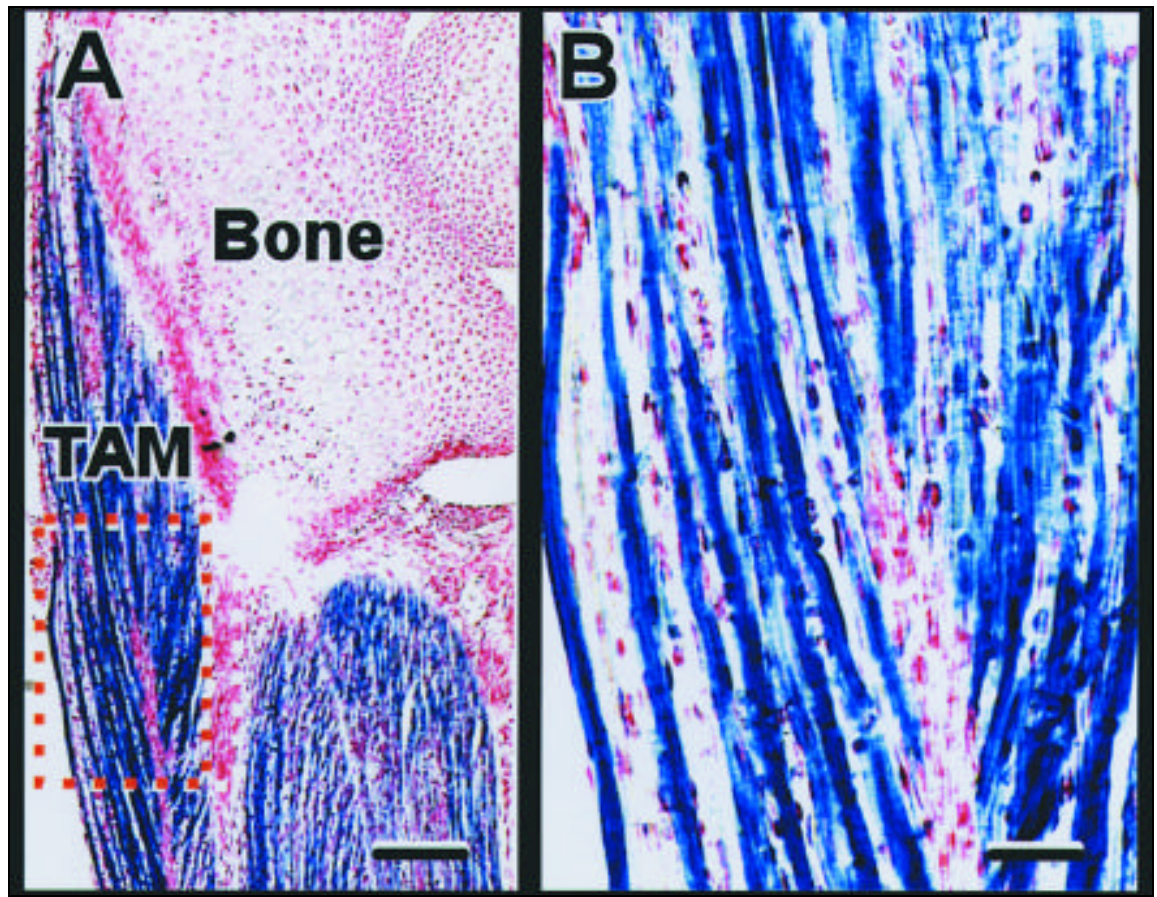

Figure 3. Histological sections of hind leg at day E18.5. (A) Tibialis anterior muscle (TAM) attached to bone; scale bar, $40 \mu \mathrm{m}$. (B) Increased magnification of orange inset shown for Panel A; scale bar, $170 \mu \mathrm{m}$. 
These clones were replica-plated onto microwells in media with and without $0.2 \mu \mathrm{M}$ FIAU. All clones grew in media without FIAU. Additionally, all seven clones targeted by gene replacement and five clones targeted by vector insertion grew in media with FIAU. By contrast, 34 clones targeted by vector insertion did not grow in media with FIAU. Therefore, of the clones targeted with MCltk to Hprt, $87 \%$ expressed the transgene at sufficient levels to confer lethality when grown in media with FIAU.

\section{DISCUSSION}

A transgenic approach was used to introduce a lacZ cassette into the Hprt gene under the regulation of myogenin regulatory sequences. The $l a c Z$ transgene was expressed in a similar temporal, spatial and tissue-specific pattern as the endogenous myogenin gene. This demonstrates, to our knowledge, for the first time, the correct tissue-specific expression pattern for a transgene targeted to Hprt. Additionally, MCltk, targeted to Hprt, was expressed at sufficient levels to confer sensitivity to FIAU for $87 \%$ of the clones. Thus, transgene expression was frequent but not absolute.

The level of staining observed for Hprt-targeted transgenic embryos appeared less intense than previously reported for transgenic mice generated by pronuclear injection (7); this might indicate reduced transcription. Transcription levels might be higher for mice generated by pronuclear injection than by targeted transgenesis due to the large number of transcriptional units that integrate into a chromosome or to integration into a locus favorable for transcription. Thus, it might not be appropriate to target transgenes with weak promoters to Hprt.

The positive-selection cassette did not appear to alter regulation of the myogenin promoter. However, there are reports that suggest the positive-selection cassette alters transcription of nearby genes $(23,27)$. The Cre/Lox system could be used to remove selection cassettes to ensure altered expression of the transgene does not occur $(1,30)$. Alternatively, the use of a positive-selection cassette can be avoided by utilizing a targeting vector that corrects for a preexisting hprt mutation in ES cells as previously described (4).

Either the Myo1565lacZ or the MCltk transgene can be removed from Hprt by intrachromosomal recombination. However, this recombination event is infrequent and was undetected in the Myo1565lacZ transgenic embryos. If selection is applied (15), transgene deletion is detectable in tissue culture cells. However, this event was not detected in any of the 34 clones that express MCltk while being grown in microwells, which demonstrates the rarity of this event.

Targeting transgenes to specific chromosomal positions offers several advantages over pronuclear injection. (i) Gene targeting reliably alters the genome in a specific location without generating unwanted mutations (17,39). Targeted cells are screened by Southern blot analysis to ensure the fidelity of the targeted locus. (ii) The level of expression can be controlled by selection for transgene number and location. All transgenes to be compared are in the same location and under the same positional effects. In certain instances, consistent level of expression is critical for comparing one transgene to another. (iii) Chimeric embryos and adults can be analyzed if a transgene produces a toxic protein that prevents transmission through the germ line. The extent of chimerism is the only variable. (iv) Because of $\mathrm{X}$-inactivation, a mosaic expression pattern is produced in hemizygous females when the transgene is located on the X-chromosome (34). The $\mathrm{X}$-chromosome is randomly inactivated in the embryo; therefore, only $50 \%$ of cells will produce the transgene product.

By taking advantage of $\mathrm{X}$-inactivation, the transgenesis technique described here can be utilized to create mosaic mice. Figure 5 summarizes a scheme to discriminate cells expressing a transgene product from non-expressing cells. Compound heterozygous female mice are generated. These mice carry different transgenes on each $\mathrm{X}$ chromosome. The transgene-of-interest (TOI) is targeted to one X-chromosome, and a lac $Z$ cassette is targeted to the other. Both TOI and lacZ cassette are under the same transcriptional regulatory sequences. Due to X-inactiva- 


\section{Research Report}

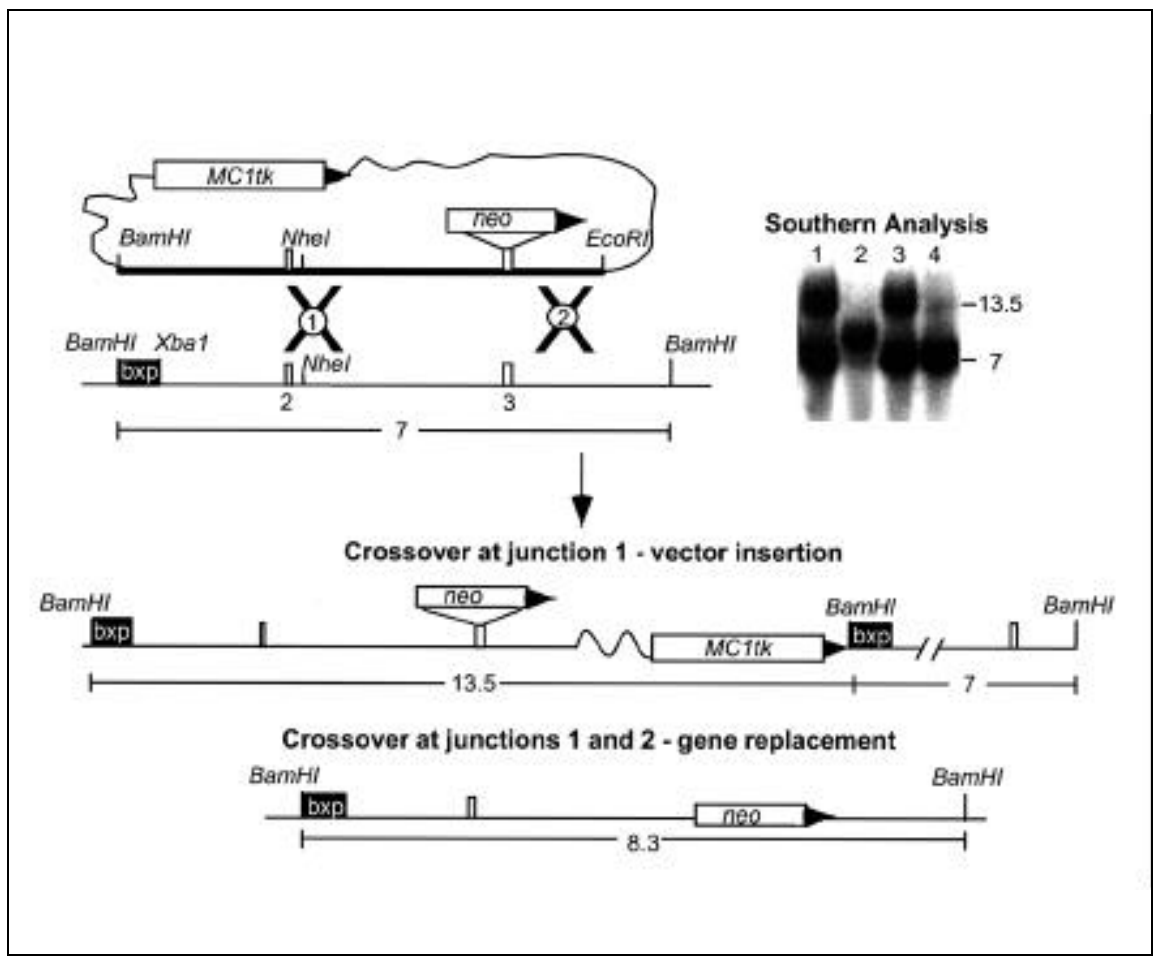

Figure 4. Targeting MCltk to hprt. Diagram same as for Figure 1. Southern analysis: DNA extracted from ES cell clones, digested with BamHI, separated by electrophoresis, blotted and hybridized to a $400-$ bp fragment from intron one release by a Bam HI-XbaI digest (BamHI-XbaI probe [bxp]). Lanes 1 and 3 are vector-insertion events (generated by a single crossover), and lane 2 is a gene-replacement event (generated by two crossovers, one on each side of PGKneobpA). Lane 4 is wild-type.

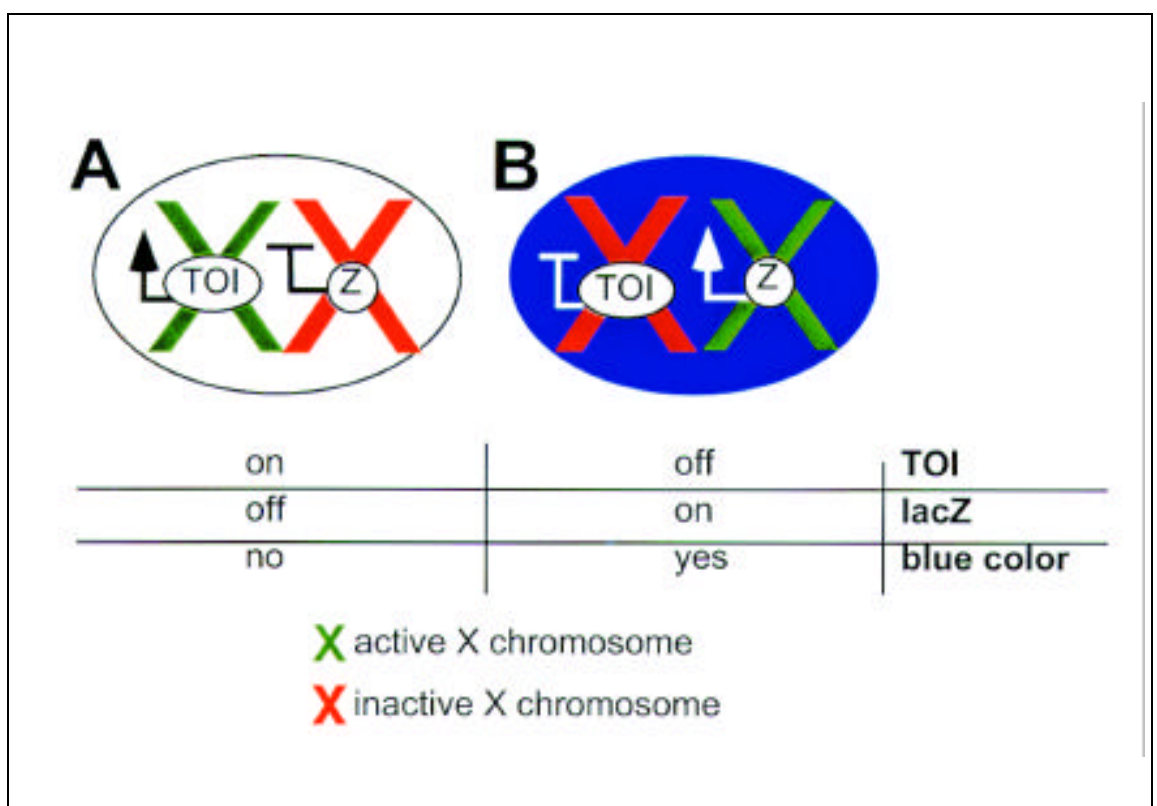

Figure 5. A scheme to identify mosaic expression of transgene targeted to Hprt. In a double-hemizygous female, the TOI is located on one $\mathrm{X}$-chromosome, and the lac $Z$ transgene $(\mathrm{Z})$ is located on the other X-chromosome. The same promoter expresses both TOI and lac $Z$. The active $\mathrm{X}$ is green, the inactive $\mathrm{X}$ is red. Vertical arrows signify transcription; vertical blocked lines signify no transcription. (A) A cell with the TOI on the active X-chromosome (TOI expressed) and lacZ on the inactive X-chromosome (lacZ silent). This cell does not stain blue in X-gal. (B) A cell with the TOI on the inactive X-chromosome (TOI silent) and lac $Z$ on the active $\mathrm{X}$-chromosome (lacZ expressed). This cell stains blue in X-gal. tion, cells will express only one of the transgenes in a given cell. Therefore, cells that express the lac $Z$ transgene do not express the TOI and stain blue after $\mathrm{X}$-Gal staining. Conversely, cells that express TOI do not express lac $Z$ and do not stain blue after X-Gal staining.

Cells that stain blue (express lacZ but not TOI) can be compared to cells that do not stain blue (express TOI but not lacZ). Comparing the distribution and number of blue cells to non-staining cells can be helpful when analyzing expression of dominant or gain of function proteins, especially if those proteins are toxic to the cell or inhibit cellular proliferation. In such a case, only blue-staining cells would survive or proliferate. Additionally, comparing blue-staining cells to non-staining cells permits investigation of cell autonomous (effects limited to within the cell expressing the TOI) and cell nonautonomous (effects not limited to within the cell expressing the TOI) functions of the transgene product.

\section{ACKNOWLEDGMENTS}

This research was supported by the National Institutes of Health (NIH) (Grant No. RO1 AR42142 to W.H.K and P.H.), the Cystic Fibrosis Foundation (to P.H.), the Muscular Dystrophy Association (to W.H.K.), a Welch grant (to W.H.K.) and a National Institute of Child Health and Human Development (NICHD) Pre- and Postdoctoral Training Grant (HD07325 to J.L.V.)

\section{REFERENCES}

1.Abuin, A. and A. Bradley. 1996. Recycling selectable markers in mouse embryonic stem cells. Mol. Cell. Biol. 16:1851-1856.

2.Al-Shawi, R., J. Kinnaird, J. Burke and J.O. Bishop. 1990. Expression of a foreign gene in a line of transgenic mice is modulated by a chromosomal position effect. Mol. Cell. Biol. 10:1192-1198.

3.Bradley, A. 1987. Production and analysis of chimeric mice, p. 113-151. In E. Robertson (Ed.), Teratocarcinomas and Embryonic Stem Cells: A Practical Approach. IRL Press, Oxford.

4.Bronson, S.K., E.G. Plaehn, K.D. Kluckman, J.R. Hagaman, N. Maeda and O. Smithies. 1996. Single-copy transgenic mice with chosen-site integration. Proc. Natl. Acad. Sci. USA 93:9067-9072. 
5.Buckingham, M. 1992. Making muscle in mammals. Trends Genet. 8:144-148.

6.Cheng, T.-C., T.A. Hanley, J. Mudd, J.P. Merlie and E.N. Olson. 1992. Mapping of myogenin transcription during embryogenesis using transgenes linked to the myogenin control region. J. Cell Biol. 119:1649-1656.

7.Cheng, T.-C., M.C. Wallace, J.P. Merlie and E.N. Olson. 1993. Separable regulatory elements governing myogenin transcription in mouse embryogenesis. Science 261:215-218.

8.Choi, T., P. Hollenback, B. Pearson, R. Ueda, G. Weddell, C. Kurahara, C. Woodhouse, R. Kay and J. Loring. 1993. Transgenic mice containing a human heavy chain immunoglobulin gene fragment cloned in a yeast artificial chromosome. Nature Genet. 4:117-123.

9.Covarrubias, L., Y. Nishida and B. Mintz. 1986. Early postimplantation embryo lethality due to DNA rearrangements in a transgenic mouse strain. Proc. Natl. Acad. Sci. USA 83:6020-6024.

10.Covarrubias, L., Y. Nishida, M. Terao, P. D'Eustachio and B. Mintz. 1987. Cellular DNA rearrangements and early developmental arrest caused by DNA insertion in transgenic mouse embryos. Mol. Cell. Biol. 7:2243-2247.

11.Edmondson, D.G. and E.N. Olson. 1989. A gene with homology to the myc similarity region of MyoD1 is expressed during myogenesis and is sufficient to activate the muscle differentiation program. Genes Dev. 3:628-640.

12.Friedrich, G. and P. Soriano. 1991. Promoter traps in embryonic stem cells: a genetic screen to identify and mutate developmental genes in mice. Genes Dev. 5:1513-1523.

13.Hanks, M., W. Wurst, L. Anson-Cartwright, A.B. Auerbach and A.L. Joyner. 1995. Rescue of the En-1 mutant phenotype by replacement of $E n-1$ with $E n-2$. Science 269:679-682.

14.Hasty, P., A. Bradley, J. Morris, H.D.G. Edmondson, J.M. Venuti, E.N. Olson and W.H. Klein. 1993. Muscle deficiency and neonatal death in mice with a targeted mutation in the myogenin gene. Nature 364:501506.

15.Hasty, P., R. Ramirez-Solis, R. Krumlauf and A. Bradley. 1991. Introduction of a subtle mutation into the Hox-2.6 locus in embryonic stem cells. Nature 350:243-246.

16.Hasty, P., J. Rivera-Perez and A. Bradley. 1991. The length of homology required for gene targeting in embryonic stem cells. Mol. Cell. Biol. 11:5586-5591.

17.Hasty, P., J. Rivera-Perez, C. Chang and A. Bradley. 1991. Target frequency and integration pattern for insertion and replacement vectors in embryonic stem cells. Mol. Cell. Biol. 11:4509-4517.

18.Jasin, M., M.E. Moynahan and C. Richardson. 1996. Targeted transgenesis. Proc. Natl. Acad. Sci. USA 93:8804-8808.

19.Kaufman, M.H. 1992. The Atlas of Mouse Development, US ed. Academic Press, San Diego.

20.Mansour, S.L., K.R. Thomas and M.R. Capecchi. 1988. Disruption of the protooncogene int-2 in mouse embryo-derived stem cells: a general strategy for targeting mutations to non-selectable genes. Nature 336:348-352.
21.McMahon, A.P. and A. Bradley. 1990. The wnt-1 protooncogene is required for the development of a large region of the mouse brain. Cell 62:1073-1085

22.Melton, D.W., D.S. Konecki, J. Brennand and C.T. Caskey. 1984. Structure, expression, and mutation of the hypoxanthine phosporibosyltransferase gene. Proc. Natl. Acad. Sci. USA 81:2147-2151.

23.Olson, E.N., H.-H. Arnold and P.W.J. Rigby. 1996. Know your neighbors: three phenotypes in null mutants of the myogenic bHLH gene MRF4. Cell 85:1-4.

24.Olson, E.N. and W.H. Klein. 1994. bHLH factors in muscle development: dead lines and commitments, what to leave in and what to leave out. Genes Dev. 8:1-8.

25.Palmiter, R.D. and R.L. Brinster. 1986. Germ-line transformation of mice. Annu. Rev. Genet. 20:465-499.

26.Ramirez-Solis, R., J. Rivera-Perez, J.D. Wallace, M. Wims, H. Zheng and $A$. Bradley. 1992. Genomic DNA microextraction: a method to screen numerous samples. Anal. Biochem. 201:331-335.

27.Ramirez-Solis, R., H. Zheng, J. Whiting, R. Krumlauf and A. Bradley. 1993. Hoxb-4 (Hox-2.6) mutant mice show homeotic transformation of a cervical vertebra and defects in the closure of the sternal rudiments. Cell 73:279-294.

28.Robertson, G., D. Garrick, W. Wu, M Kearns, D. Martin and E. Whitelaw. 1995. Position-dependent variegation of globin transgene expression in mice. Proc. Natl. Acad. Sci. USA 92:5371-5375.

29.Sandgren, E.P., R.D. Palmiter, J.L. Heckel, C.C. Daugherty, R.L. Brinster and J.L. Degen. 1991. Complete hepatic regeneration after somatic delection of an albumin-plasminogen activator transgene. Cell 66:245-256.

30.Sauer, B. 1993. Manipulation of transgenes by site-specific recombination: use of Cre recombinase, p. 890-900. In P.M. Wassarman, and M.L. DePamphilis (Eds.), Guide to Techniques in Mouse Development, Vol. 225. Academic Press, Pasadena.

31.Schnieke, A., K. Harbers and R. Jaenisch. 1983. Embryonic lethal mutation in mice induced by retrovirus insertion into the alpha1(I) collagen gene. Nature 304:315-320.

32.Shaw-White, J.R., N. Denko, L. Albers, T.C. Doetschman and J.R. Stringer. 1993. Expression of the lacZ gene targeted to the HPRT locus in embryonic stem cells and their derivatives. Transgenic Res. 2:1-13.

33.Soriano, P., R.D. Cone, R.C. Mulligan and R. Jaenisch. 1986. Tissue-specific and ectopic expression of genes introduced into transgenic mice by retroviruses. Science 234:1409-1413.

34.Tan, S.-S., E.A. Williams and P.P.L. Tam. 1993. X-chromosome inactivation occurs at different times in different tissues of the postimplantation mouse embryo. Nature Genet. 3:170-174.

35.Wang, Y., P. Schnegelsberg, J. Dausman and R. Jaenisch. 1996. Functional redundancy of the muscle-specific transcription factors Myf5 and myogenin. Nature 379:823-825.

36.Woychik, R.P., T.A. Stewart, L.G. Davis, P.D. D'Eustachio and P. Leder. 1985. An inherited limb deformity created by insertional mutagenesis in a transgenic mouse. Nature 318:36-40.

37.Wu, C.-L. and D.W. Melton. 1993. Production of a model for Lesch-Nyhan syndrome in hypoxanthine phosphoribosyltransferase-deficient mice. Nature Genet. 3:235-239.

38.Zhang, H., P. Hasty and A. Bradley. 1994 Targeting frequence for deletion vectors in embryonic stem cells. Mol. Cell. Biol. 14:2404-2410.

39.Zheng, H., P. Hasty, M. Brennenman, M. Grompe, R. Gibbs, J. Wilson and A. Bradley. 1991. Fidelity of targeted recombination in human fibroblasts and murine embryonic stem cells. Proc. Natl. Acad. Sci. USA 88:8067-8071.

Received 23 March 1998; accepted 25 March 1999.

Address correspondence to:

Paul Hasty

Lexicon Genetics

4000 Research Forest Drive

The Woodlands, TX 77381, USA

Internet: phasty@lexgen.com 